\title{
A PRESENÇA DA PAIDEIA NA PEDAGOGIA DE PAULO FREIRE: UMA PROPOSTA DE EDUCAÇÃO CIDADÃ
}

\author{
Ana PAULA WALTRICK \\ Universidade do Planalto Catarinense (UNIPLAC), Lages, Santa Catarina, Brasil \\ VANICE dOS SANTOS \\ Universidade Federal da Paraíba (UFPB), Bananeiras, Paraíba, Brasil \\ Maria Selma Grosch \\ Universidade do Planalto Catarinense (UNIPLAC), Lages, Santa Catarina, Brasil
}

\begin{abstract}
REsUMo: O presente artigo se caracteriza como uma pesquisa bibliográfica de caráter qualitativo, apresentada no Mestrado em Educação, propondo-se a descrever as aproximações e distanciamentos observados entre a paideia, desenvolvida na Antiguidade, e a educação libertadora, proposta pelo educador brasileiro Paulo Freire. O fortalecimento da filosofia na Grécia Clássica permitiu constituir novas relações que priorizavam, principalmente, a participação social dos cidadãos gregos. Paulo Freire embasa seus princípios educativos na dialogicidade, na autonomia e na defesa dos direitos essenciais a todos. Nesse sentindo, a educação cidadã, descrita em ambos, enaltece o ser humano como capaz de transformar suas realidades frente à sua humanização e ao seu entendimento de inacabamento que o conduz a um contínuo processo educativo.
\end{abstract}

Palavras-chave: Fundamentos da Educação. Paideia. Paulo Freire. Educação libertadora.

\section{INTRODUÇÃO}

A sociedade grega se consolidou ao longo da Antiguidade e constitui referências para o comportamento e pensamento das posteriores sociedades ocidentais. Nesse sentido, os gregos contribuíram também para a concepção dos princípios educativos que se refletiram na educação de seu povo e daqueles que herdaram seus valores, seus conhecimentos e suas práticas sociais. Entre as contribuições dos povos da Grécia Antiga', temos a Filosofia, um conjunto de reflexões sobre as relações humanas entre si e com o mundo. Considerado como uma criação tipicamente dos gregos (CHAUI, 2001), o pensamento filosófico perpassou por séculos e está presente enquanto possibilidade de observações críticas frente ao contexto atual.

A trajetória da Grécia na Antiguidade compreende diversas transformações sociais e territoriais ao longo dos séculos em que ocuparam as regiões do Mar Egeu, Península Balcânica e Ásia Menor. O comércio marítimo, a agricultura e as conquistas geradas pelo enfrentamento nos conflitos fizeram com que os gregos se consolidassem economicamente e, assim, desenvolvessem seus espaços urbanos que atingiram seu 
auge com as polis ou cidades-estados. Nesses espaços, surgiram a filosofia, a política e a educação, pensadas enquanto atitudes inerentes à essência humana e que se tornaram objeto de estudo dos pensadores antropológicos da Antiguidade.

Face a esse contexto, a filosofia teve seu início por volta do século VI a.C., quando os primeiros pensadores se dedicaram à compreensão do surgimento do universo e do funcionamento da natureza. Desse modo, o pensamento filosófico se propunha a buscar explicações que se distanciassem da mitologia criada pela tradição religiosa dos gregos e, assim, encontrar no uso da racionalidade métodos para se observar, refletir e criticar aquilo que os rodeava. Foi a partir da influência dos filósofos sofistas e de Sócrates de Atenas que os pensadores voltaram seus olhares para as questões humanas e sociais em seus contextos históricos.

A educação, enquanto atividade humana, também se constituiu ao longo dos séculos no território grego. A educação surgiu vinculada a arete $^{2}$, compondo o preparo dos guerreiros e a formação política, sendo que a idealização heroica dos homens esteve inspirada nas figuras mitológicas, como as de Aquiles e Heitor. Os princípios educativos inspirados nos poemas homéricos compreendiam a importância da formação dos valores e comportamentos da sociedade grega, sendo que o exemplo dos heróis (CAMBI, 1999) motivava o caminho para o preparo dos cidadãos.

Essa proposta de educação grega era destinada aos aristocratas, ou seja, para os grupos sociais com maior influência e poder de governança nos centros urbanos. $O$ pensamento educativo, assim como a participação social e a tomada de decisões, eram limitados aos homens que detinham a posse de terras e escravos, acontecendo no espaço público denominado Ágora ${ }^{3}$. À medida em que os gregos realizavam novas conquistas e estabeleciam novas relações econômicas, a polis ${ }^{4}$ se consolidava e nesse mesmo sentido, os valores e os princípios se alteravam.

Com o fortalecimento das cidades-estados e o auge do desenvolvimento social e cultural da Grécia Antiga, a filosofia se estruturou a partir das explicações provenientes dos mitos. Foi com os filósofos gregos do período antropológico que as questões humanas passaram a ser o foco das reflexões e, com isso, a educação sofreu transformações. Assim, a partir do século V a.C. surge a concepção de paideia ${ }^{5}$, pautada na formação humana englobando o preparo do corpo (físico) e do espírito (intelectual). Esse modelo educacional, proposto pelos gregos, se consolidou somente no século IV a.C., tendo como principais pensadores: Sócrates, Platão - ambos de Atenas - e Aristóteles de Estagira.

A paideia concebida pelos gregos era constituída, além da educação, por valores culturais, estéticos, filosóficos, morais e políticos que faziam parte daquela sociedade. É nesse sentido que Jaeger (2001) compreende a complexidade deste conceito, idealizado pela civilização grega na Antiguidade. Os princípios pedagógicos desses povos visavam ao preparo dos cidadãos para tomar as decisões da polis e, assim, para o exercício da democracia, preceito também originário da Grécia Antiga. É com os filósofos que a racionalidade emana como capacidade humana de observar o contexto a partir de sua própria existência.

Os valores e concepções constituídos pela paideia fazem parte da herança cultural deixada pela Grécia ao mundo Ocidental. Desse modo, a educação concebida 
pelas sociedades atuais tem sua origem nos fundamentos dos povos helenos ${ }^{6}$, quando os filósofos gregos passaram a compreender os seres humanos como capazes de observar sua realidade por meio da racionalidade. Assim, a educação, enquanto paideia, envolvia-se essencialmente na formação humana e, consequentemente, se integrava às dinâmicas sociais (CAMBI, 1999) inerentes aos diferentes grupos que compunham a polis.

A contribuição da filosofia para a educação constituiu o campo da filosofia da educação que auxilia nas reflexões acerca das ações pedagógicas até a atualidade. Sócrates desdobrou o seu pensamento utilizando o método da maiêutica socrática ${ }^{7}$ por meio do diálogo. Já Platão, idealizador da Academia (um espaço de diálogo e construção de conhecimento), argumenta acerca de uma dualidade física e metafísica da existência a partir da teoria das ideias, propondo uma base utópica da realidade. Esse filósofo também se dedicou em elaborar propostas pedagógicas que compreendem a educação como ato político.

Ainda, Aristóteles, discípulo de Platão e fundador do Liceu (lugar de preparo dos jovens atenienses), buscou propor a cientificidade no pensamento filosófico a partir da teoria do movimento e da organização das ciências, das quais a filosofia é o princípio. Esse filósofo também foi preceptor do imperador macedônico Alexandre Magno, contribuindo para a expansão do helenismo nas regiões conquistadas e, consequentemente, para a ascensão das civilizações greco-romanas. Cabe destacar que, conforme ordem apresentada aqui, cada filósofo, inicialmente discípulo, com a dedicação empenhada no fazer filosófico, tornou-se mestre posteriormente.

A partir das concepções educativas criadas pelos gregos, na Antiguidade, a educação ocidental se estruturou tendo a herança helênica como referência. No Brasil, tal influência ascendeu a partir dos processos de colonização europeia, principalmente, com a presença dos portugueses e missões religiosas. Nesse sentido, compreender a gênese dos princípios pedagógicos ocidentais é, de certo modo, compreender a trajetória educativa brasileira.

Todavia, é relevante pontuar que a educação em nosso país não se reduz a influências estrangeiras em seu modo de ação e reflexão, há proeminentes contribuições nacionais, com destaque para o educador Paulo Freire, patrono da educação brasileira. $\mathrm{Na}$ obra freireana há uma característica de referir-se à realidade das professoras e professores, bem como de estudantes que se encontram em situação de vulnerabilidade ou em regiões periféricas. Freire sinaliza que a educação é o caminho que gera a transformação social. As proposições da educação libertadora são pautadas, principalmente, na dialogicidade, na práxis pedagógica e na valorização das relações entre docentes e discentes visando à possibilidade de mudança social.

Desde seu primeiro escrito, Paulo Freire opõe-se ao modelo tradicional bancário ${ }^{8}$ de educação, tendo suas críticas e apontamentos descritos na obra Pedagogia do Oprimido (FREIRE, 2014a). Nesse sentido, o educador constitui um método de ensino e aprendizagem no qual a práxis pedagógica nasce a partir do cotidiano dos educandos, das suas palavras e vivências. A educação libertadora supera dicotomias preestabelecidas pelo sistema educacional vigente, como o acesso ao conhecimento, valorizando os educandos como capazes de aprender e transformar sua realidade.

Nessa concepção, a ação pedagógica libertadora, em que Paulo Freire baseou seus princípios, parte de uma práxis que enaltece o conhecimento dos educandos e 
educadores que se constroem enquanto seres humanos capazes por meio da educação. A dialogicidade freireana se fundamenta e dá sentido às vivências educacionais, motivando o contínuo aprendizado gerado por nossa condição humana de inacabamento (FREIRE, 2014b). Ao desenvolver as capacidades cognoscentes de desvelar seu mundo, o educando, assim, passa a também tornar-se cidadão em uma perspectiva ampla na conquista de seus direitos.

Com isso, Paulo Freire andarilhou por preceitos e conceitos aos quais os filósofos humanistas da Antiguidade também percorreram ao longo de suas vivências. Assim sendo, ao observarmos a gênese da educação ocidental a partir da paideia, percebemos que existem aproximações nos ideais da Grécia Antiga ao buscar uma educação cidadã e as obras freireanas que buscam a emancipação do sujeito dentro dos princípios democráticos. No entanto, cabe pontuar que, no decurso deste artigo, será levado em consideração a temporalidade e os contextos pertinentes a cada período compreendido, Antiguidade e Contemporaneidade e, desse modo, também perceber os distanciamentos existentes.

A partir do exposto, a construção deste artigo parte de uma abordagem qualitativa, pois, no entendimento de Minayo (2016), se caracteriza por observar as práticas humanas, possibilitando assim relações relevantes às sociedades. $O$ percurso metodológico deste artigo é caracterizado como uma pesquisa bibliográfica que elenca materiais já existentes (GIL, 2018), entendendo-se que a partir da reunião de fontes e ideias, novas compreensões acerca do tema pesquisado são constituídas. Tem-se como proposta identificar as relações entre a paideia e a educação libertadora, descrevendo os princípios filosóficos e educacionais legados pelos gregos às sociedades ocidentais, e apresentando a pedagogia criada por Paulo Freire, bem como as aproximações e distanciamentos entre os temas.

As discussões apresentadas sobre a paideia partem dos escritos de Jaeger (2001), Cambi (1999), Chaui (2001), Cenci; Dalboco e Mühl (2009), Aranha (2006a; 2006b) e de $A$ República de Platão (2001), pensador considerado referência para as reflexões filosóficas do Ocidente. A educação libertadora tem seus princípios descritos nas obras de Paulo Freire (2014a; 2014b; 2015), Freire e Faundez (2019) e Zitkoski (2010). As aproximações existentes entre esses princípios educativos demonstram a atemporalidade com o estudo dos acontecimentos humanos, entre eles, a política, as relações sociais e o diálogo, demonstrando a atualidade existente nos escritos filosóficos freireanos.

\section{A EDUCAÇÃO COMO PRÁTICA HUMANA}

A educação enquanto ação humana faz parte do cotidiano das sociedades desde os primórdios da Antiguidade. Os grupos humanos têm como inerente a transmissão das suas práticas e hábitos culturais às gerações seguintes e assim auxiliar os jovens e crianças em seu ingresso nos meios sociais, possibilitando o desenvolvimento dos espaços urbanos e da própria ciência (ARANHA, 2006a). Nesse sentido, são os gregos, ao longo de sua trajetória no período antigo, que estruturam os 
WALTRICK, A. P.; SANTOS, V.; GROSCH, M. S

fundamentos dos princípios educacionais para as sociedades ocidentais. Segundo Jaeger (2001, p. 4),

toda educação é assim o resultado da consciência viva de uma norma que rege uma comunidade humana [...]. A educação participa na vida e no crescimento da sociedade, tanto no seu desenvolvimento espiritual; e, uma vez que o desenvolvimento social depende da consciência dos valores que regem a vida, a história da educação está essencialmente condicionada pela transformação dos valores válidos para cada sociedade [...].

Em consonância com os escritos do filólogo alemão Jaeger, ao resgatar os valores sociais, políticos e culturais deixados pelos gregos na Antiguidade, percebemos a necessidade da educação como um meio pelo qual os seres humanos se compreendem em suas vivências sociais. As sociedades que alcançam progressos tendem a praticar a educação (JAEGER, 2001) na busca de atender às conjunturas de cada povo, como seus valores, ideias e crenças. A consciência humana se desenvolve pelas atividades educacionais e, assim, procura entender a si e o mundo que a cerca.

A cada época e contexto, as demandas educativas foram se transformando, assim como as construções sociais. Nessa lógica, "[...] nascemos como possibilidade e vamos nos tornando seres humanos concretos por meio da educação, que nos permite incorporar o que foi criado pela própria espécie humana no decorrer de sua história [...]" (CENCl; DALBOSCO; MÜHL, 2009, p. 90). Ou seja, é por meio da educação que o ser humano tem a possibilidade de acessar os conhecimentos, produzidos pelas gerações que os antecederam, e aprimorá-los. Desse modo, o caminho da humanidade ao longo do tempo tem na educação um fundamento essencial para a transformação e desenvolvimento das sociedades.

A trajetória educacional da Grécia Antiga, na qual o Ocidente ancora seus fundamentos, perpassou por uma série de transformações. Os primórdios educacionais gregos têm suas raízes nos tempos homéricos com a transmissão oral de contos mitológicos por aedos e rapsodos ${ }^{9}$ em espaço público, enfatizando as virtudes de um herói idealizado, configurando-se como principais exemplos de obras do período, quais sejam, as epopeias llíada e Odisseia ${ }^{10}$ de Homero. Dessa forma, a educação apresentava um caráter inconsciente de preparo para as atividades intrínsecas do cotidiano, como a veneração aos deuses e o aprendizado de ofícios como techne ${ }^{17}$.

A concepção de educação na Grécia Antiga sofre alterações no período arcaico com o surgimento da arete, um conceito de difícil definição, recebendo uma atribuição geral como as virtudes ligadas a uma conduta essencialmente humana na busca pelo aperfeiçoamento. Entende-se que "[...] a arete é o atributo próprio de nobreza. Os gregos sempre consideraram a destreza e a força incomuns como base indiscutível de qualquer posição dominante [...." (JAEGER, 2001, p. 26, grifo do autor). A base da arete reside nos arquétipos dos heróis gregos descritos nos mitos, destacando atributos como: beleza, justiça e bondade como ideal educativo para o exercício militar e a liderança do espaço urbano.

No período clássico ou antropológico, com o auge das cidades-estados, é possível identificar a consolidação da filosofia. Esse fator estimulou o uso da 
racionalidade como instrumento do saber, percepção, reflexão e crítica. Assim, a arete, por meio dos sofistas, considerados os primeiros educadores, é transformada de forma gradativa, voltando-se ao entendimento da historicidade do ser e da educação de forma contínua e integral, caracterizando o primórdio da paideia. O conceito de paideia (JAEGER, 2001) surge no século $V$ a.C. e tem seu auge no século IV a.C., podendo ser definido, em um primeiro momento, como a criação dos meninos.

A noção de educação, ou seja, de paideia grega, precisa ser situada no contexto da compreensão que os gregos possuíam originariamente de filosofia, a qual consistia, primordial e basicamente, numa opção, num modo de viver segundo o qual se discerniam atos e intenções à luz do bem, do belo, do justo, do verdadeiro [...] (CENCl; DALBOSCO; MÜHL, 2009, p. 105).

Com base nisso, sabe-se que os principais filósofos da Antiguidade grega, enfatizando Sócrates, Platão e Aristóteles, fizeram consideráveis contribuições para a paideia como princípio e modelo educacional. Em seus diálogos, Sócrates discute o desenvolvimento de uma educação humanizada e fundamentada na criticidade e dúvida por meio do questionamento do conhecido e do desconhecido para construção de conceitos verdadeiros e duradouros. Dessa forma, o pensador estimulava o reconhecimento da ignorância do ser frente ao saber e a dialogicidade entre os indivíduos envolvidos no processo pedagógico. Ainda, de acordo com Sócrates, por meio do diálogo e a revisita ou a descoberta de conceitos é que a maiêutica, caracterizando, de forma ampla, como o parto de ideias poderia acontecer. Sabe-se que Sócrates foi condenado à morte acusado de corromper a juventude ateniense, já que rompia com os paradigmas e as estruturas sociais vigentes ao questionar a realidade.

Já as concepções de Platão para a paideia (inicialmente discípulo de Sócrates, e, posteriormente mestre) envolveram uma abordagem essencialmente política do aprendizado, voltada ao preparo ético e moral do cidadão da polis para as atividades do cotidiano. Além disso, as ideias platônicas também circundavam uma abordagem fundamentada na dualidade da matéria e das virtudes, a chamada teoria das ideias. Isso é, o filósofo defendia a existência de um mundo inteligível e ideal no qual as versões perfeitas de todos os objetos, ideias e seres residiam, "[...] e diremos ainda que aquelas são visíveis, mas não inteligíveis, ao passo que as ideias são inteligíveis, mas não visíveis" (PLATÃO, 2001, p. 305), enquanto na esfera física cópias imperfeitas dessas mesmas versões poderiam ser encontradas.

Platão aborda essa dualidade entre o mundo físico e inteligível das ideias por meio da alegoria caverna. Presos nessa caverna, os sujeitos são abstraídos do mundo real, sendo submetidos a apenas sombras, cópias imperfeitas dos constructos metafísicos verdadeiros, só podendo se libertarem das amarras do perceptível imperfeito mundano a partir do filósofo guia. Dessa forma, o pensador explicava a diferença entre os seres e objetos, bem como as suas relações com as ideias e embasava sua teoria de que, por meio do conhecimento e aprendizado, seria possível se aproximar 
WALTRICK, A. P.; SANTOS, V.; GROSCH, M. S

das versões ideais das coisas e do ser, ou seja, a partir do conhecimento idealizado e perfeito.

Aristóteles, outrora discípulo de Platão, destoa de seu mestre ao adotar uma abordagem concreta de estudo das coisas, a partir delas mesmas, por meio da teoria do movimento. Entende-se que as coisas apresentam uma essência intrínseca que as caracteriza como aquilo que são e uma potência que permite sua transformação em outra coisa, ou seja, sua concretização em ato, abandonando a necessidade de explicações metafísicas de um mundo inteligível das ideias. Assim, por meio da repetição das atividades, ou seja, o aperfeiçoamento da potência das coisas, os indivíduos seriam capazes de exercer a mudança e aperfeiçoar o conhecimento. Além disso, o pensador também se dedicou à sistematização do conhecimento em diferentes áreas, contribuindo para o desenvolvimento dos currículos, apresentando uma perspectiva realista das segregações e problemas sociais na polis.

Diferentemente de Sócrates, que identificava saber e virtude, Aristóteles enfatizava a ação da vontade, exercitada pela repetição, que conduz ao hábito da virtude. Daí a imitação ser o instrumento por excelência desse processo, segundo o qual a criança se educa repetindo os atos de vida dos adultos, adquirindo hábitos que vão formar uma 'segunda natureza' (ARANHA, 2006b, p. 75).

A paideia grega tem como princípios a educação integral e contínua do indivíduo para as atividades políticas e socioculturais da polis. Sabe-se que essa educação era destinada aos cidadãos, na condição grega, ou seja, aos homens que tinham posses e que eram maiores de vinte e um anos, ou seja, à aristocracia e comerciantes locais. Em relação aos demais povos existentes na Antiguidade, que em sua maioria eram governados por regimes teocráticos e monárquicos, essa concepção de cidadania, embora limitada, era um avanço ao garantir os princípios democráticos.

Em suma, a importância da paideia para as concepções de educação no Ocidente reside na noção de uma educação que envolve o preparo intelectual e físico dos educandos, bem como a interação e dialogicidade entre todos os envolvidos no processo pedagógico. Ainda, a paideia grega norteia modelos educacionais ao estimular a indagação e a criticidade como instrumentos de descoberta e aprimoramento do conhecimento, dentro e fora da sala de aula. Assim, a proposta pedagógica embasada nessas ideias permite a formação de sujeitos críticos e efetivamente participantes de seus meios sociais.

\section{POR UMA EDUCAÇÃO CIDADÃ NA PERSPECTIVA LIBERTADORA}

Na atualidade, novas perspectivas pedagógicas têm emergido, desvelando as realidades que segregam aqueles que se encontram em situação marginalizada frente à sociedade contemporânea. A partir disso, o educador Paulo Freire tem como cerne de seu pensamento o rompimento das exclusões sociais e a reflexão acerca da efetiva participação dos sujeitos em seus espaços sociais. Além de criticar as concepções educacionais vigentes que estabelecem dicotomias, preconceitos e violências que revelam problemas sociais. 
Entende-se que essas circunstâncias estão interligadas às práticas docentes que corroboram a perpetuação das realidades vigentes que, por vezes, mantém os educandos em situação de alienação quanto ao processo pedagógico e à sua efetiva participação social. Paulo Freire sinaliza suas preocupações com o modelo educativo que denominava como educação bancária: "Desta maneira, a educação se torna um ato de depositar, em que os educandos são os depositários e o educador, o depositante" (FREIRE, 2014a, p. 80). Nessa perspectiva, o educador pontua sobre a inexistência da possibilidade de diálogo entre educandos e educadores, e evidencia a dicotomia entre opressores e oprimidos.

Como possibilidade para romper as relações estabelecidas pela educação bancária, Paulo Freire propõe, em sua práxis, uma educação embasada nos princípios de liberdade, autonomia, reconhecimento da trajetória histórica e social dos educandos e educadores e, principalmente, a dialogicidade como sustentação do processo pedagógico. Dessa forma, o educador estabelece a educação libertadora ou problemática. Em suas primeiras vivências pedagógicas, Freire buscou aplicar essas concepções na alfabetização de jovens e adultos por meio dos temas geradores. Esse método compreendia o aprendizado da leitura do mundo dos sujeitos para, assim, aprenderem a pensar certo (FREIRE, 2014a).

Ainda destacamos que a constituição da práxis freireana provém da relação entre educandos e educadores que juntos colaboram para a construção do conhecimento, não mais em patamares diferentes, mas ambos vistos como essenciais. Segundo Freire (2014b, p. 24), “[...] assumindo-se como sujeito também da produção do saber, se convença definitivamente de que ensinar não é transferir conhecimento, mas criar as possibilidades para sua produção ou a sua construção". A práxis em Freire é definida como ação-reflexão das vivências educativas em que o compromisso é promover ações que instiguem a criticidade e a consciência de sua realidade social para então se libertar. Assim,

\begin{abstract}
ao colocar o diálogo como condição primeira da libertação dos oprimidos, Freire fundamenta o projeto de transformação social em bases renovadas que convergem para a humanização sociocultural da humanidade em seu todo. A dialogicidade é a prática do diálogo verdadeiro, que mantém viva a dialeticidade entre ação e reflexão. [...]. É pelo diálogo que implica uma atitude de vida, que os homens e as mulheres constroem um mundo humano, de modo a refazer o que já existe e projetar um futuro que está por realizar-se (HAMMES; ZITKOSKI; BOMBASSARO, 2018, p. 1015, grifo dos autores).
\end{abstract}

O caminho para a concretização da educação libertadora tem como um dos fundamentos a dialogicidade. Nesse sentindo, o diálogo permite aos educandos e aos educadores reconhecerem suas trajetórias de vida, ou seja, perceberem suas histórias e a partir disso, constituir as relações humanas inerentes ao processo educativo. Paulo Freire aponta que a mudança é fundamentada no pronunciar as palavras, algo que é essencialmente humano e permite a defesa e o rompimento das condições da realidade: opressor e oprimido. É por meio do diálogo que a educação problematizadora percebe 
os sujeitos como seres providos de humanidade, ou seja, que estão em constante transformação.

As proposições freireanas destacam a importância da participação social dos indivíduos como sujeitos de pleno direito, autônomo e crítico. Essa possibilidade humana se concretiza quando o oprimido se percebe enquanto liberto das amarras sociais que inviabilizam o acesso à educação. Nesse sentido, Paulo Freire defende a democratização do ato de ensinar-aprender, pois "não teremos uma nova educação se não tivermos uma educação em constante renovação" (FREIRE, 2019, p. 132). Desse modo, o educador brasileiro defendia que a educação é o caminho pelo qual os seres humanos se humanizam, se constituem enquanto agentes sociais e, portanto, ao trilhar o caminho escolhido (FREIRE, 2015), é preciso integrar-se e oportunizar que outras pessoas também se sintam parte do processo pedagógico.

A relevância dos escritos de Paulo Freire ultrapassa as fronteiras da educação brasileira, pois enquanto andarilho da esperança, o educador demonstrou a importância do ato educativo dialógico para que exista uma relação cognoscente mútua entre os sujeitos. Dessa forma, a educação cidadã, pensada por Freire, pretende evidenciar as capacidades humanas de refletir, criticar e transformar seu contexto social para uma participação ativa e pautada na ampla cidadania. Nota-se que alguns desses princípios também podem ser identificados na proposta pedagógica da paideia grega, descrita pelos filósofos da Antiguidade clássica.

\section{A PRESENÇA DA PAIDEIA GREGA NOS PRINCÍPIOS FREIREANOS}

Os princípios da paideia grega perpassaram os séculos, e seus conceitos se mantêm relevantes atualmente, considerando a distância cronológica e temporal. Aspectos convergentes, como o preparo dos educandos para a cidadania, a autonomia e criticidade na busca pelo conhecimento e em seu aprimoramento, além do exercício do diálogo como ocasiões para o movimento de inquietações para o intercâmbio de saberes e experiências, podem ser identificados tanto na paideia como na pedagogia de Paulo Freire. Ainda é possível identificar divergências, principalmente, relacionadas à segregação dos sujeitos quanto ao acesso às decisões ligadas ao Estado.

As propostas dos principais filósofos da Antiguidade grega, Sócrates, Platão e Aristóteles também podem ser correlacionadas a princípios das pedagogias freireanas. Isso é notado na forma como o educador brasileiro estruturou sua práxis-educativa e na sua relação com os ideais gregos, enfatizando a presença da herança dos helenos. Assim, através do autorreconhecimento da condição de oprimido por meio da leitura de sua realidade e reflexão, o educando pode se tornar um agente de mudança, superando a dicotomia entre opressor e oprimido (FREIRE, 2014a).

Um primeiro ponto de convergência entre a paideia grega e Freire está na aproximação da educação problematizadora com a maiêutica socrática. Sócrates estimulava o reconhecimento da ignorância do sujeito frente ao saber, permitindo assim a construção do saber verdadeiro através da indagação. Freire, de forma similar, em sua práxis defende o autorreconhecimento do educando em sua condição de oprimido, buscando assim os meios necessários para romper com os laços de opressão, ou seja, para libertar-se e transformar o meio para que então ocorra a construção de um 
conhecimento real, aplicado e condizente com sua realidade. Nesse sentido, o diálogo para Sócrates permite aprimorar ou formular conhecimento a partir de questionamentos e para Freire ele é uma ferramenta de transformação, autorreconhecimento e efetivação social.

Outra considerável aproximação pode ser identificada em um espectro antropológico e político da educação. Platão dirigiu considerável atenção em um primeiro momento para o estudo da justiça, da verdade, do belo, da moral e da ética em sua obra $A$ República, perpassando então o campo da educação. Assim, para o pensador o ato de educar era político ao preparar os cidadãos para as atividades da polis, centrado na formação integral e contínua dos educandos. Freire se aproxima dessas ideias ao propor um processo educativo voltado à realidade do educando, isso é, essencialmente humano no sentido de compreender sua trajetória histórica e realidade, inevitavelmente política, ao julgar impossível abordar um tema de forma neutra, um ponto importante na conscientização do discente quanto à sua condição e sua libertação.

Além desses pontos, a convergência entre a teoria do movimento de Aristóteles e a educação libertadora de Freire também é relevante. Na teoria aristotélica do movimento, o ser ou objeto possui uma essência intrínseca que pode ser transformada e concretizada em ato através de uma potência, explicando as diferenças existentes na esfera física e permitindo estabelecer métodos de aprimoramento do conhecimento a partir da repetição, ou seja, do treino e hábito para efetivação de uma virtude. De forma similar, na proposta freireana, o educando apresenta a potência, ou seja, a sua capacidade de autorrealização enquanto oprimido, permitindo a sua transformação e concretização em ato com a sua libertação, "nesse sentido, Freire define o conceito de corpo consciente como base para superar a histórica dicotomia corpo-espírito e sentidos-razão, que predominou na filosofia ocidental e continua hoje na raiz dos processos culturais opressores e alienantes da existência humana [...]" (ZITKOSKI, 2010, p. 22). Ressalta-se ainda que ambos os pensadores adotavam uma postura pragmática de reconhecimento da existência de segregação de classes em relação ao acesso à educação.

Ainda é possível estabelecer algumas considerações gerais acerca das principais diferenças e similaridades entre a paideia e a educação problematizadora freireana. As duas propostas se baseiam na reflexão como instrumento de mudança ou aprendizado, seja aplicada à práxis-educativa ou às ações humanas em uma abordagem fundamentalmente relacionada ao cotidiano dos envolvidos no processo. Enfatizando a formação de maneira integral, ligada à conscientização e inclusão de todos os indivíduos no processo educativo, em Freire, ou exclusivamente voltado às atividades da polis, na concepção dos pensadores gregos. Além disso, a proposta grega de paideia e a educação freireana se aprofundaram na sistematização do conhecimento buscando contextualizar a prática pedagógica à realidade dos educandos, no caso de Freire, ou para sistematizar o estudo das implicações e aspectos do conhecimento em diferentes áreas do saber, para os gregos.

Dessa forma, tanto na paideia grega, como na educação libertadora de Freire, o ser humano é considerado inacabado e, muitas vezes, alienado da sua realidade. Assim, a educação se configura como uma possibilidade de libertação e humanização através 
do aprendizado e aprimoramento do conhecimento, identificando-se confluência entre os diferentes conceitos e ideias discutidos nos escritos dos filósofos apresentados e a educação libertadora freireana. Assim, se almeja a humanização e democratização do processo pedagógico, "Paulo Freire contradiz esse pensamento pedagógico segregador, identifica-se como educador, em defesa da formação humana ao longo de todos seus escritos e de suas práticas. Não pensa os oprimidos como não humanizáveis, mas como humanos já. [...]" (ARROYO, 2019, p. 5). Nesse sentido, Freire argumenta em defesa de uma dinâmica humana de formação e de interação entre educando e educador, promovendo a integração e intencionalidade do aprendizado.

Dessa forma, entende-se que, embora haja considerável distância temporal entre a paideia grega e os conceitos de Paulo Freire, as contribuições dos gregos para os modelos educacionais Ocidentais e, especialmente, para as pedagogias freireanas são evidentes. Pois, apesar de diferentes, as concepções de cidadania e de acesso à educação são pontos-chaves entre esses dois eixos, compreendendo-se que as duas propostas confluem na formação de um sujeito ativo, efetivo, autônomo, crítico e político. Desse modo, o indivíduo é reconhecido como um agente em seu meio, podendo vir a transformar a sua realidade e a de outros, não somente no ambiente educativo, mas nas mais diversas esferas sociais, dentro do seu contexto sócio-histórico.

\section{CONSIDERAÇÕES FINAIS}

A paideia grega, enquanto fundamento educativo para as sociedades ocidentais, considera a educação integral para a formação das capacidades humanas intelectuais e corporais. Além disso, a filosofia se integra à educação ao longo da história da Grécia Antiga e constitui um campo de conhecimento denominado de Filosofia da Educação. Ela auxilia a pedagogia ao observar, refletir e problematizar sobre as vivências dos espaços educativos.

Os escritos de Paulo Freire convergem com a paideia, constituída pelos gregos, com destaque para a importância dada à dialogicidade e pela capacidade de instigar questionamentos, criada por Sócrates em seu método denominado maiêutica. A proposta de educação libertadora pontua o ato de educar-aprender enquanto ato político, que assume o cuidado com a valorização da constituição dos valores éticos e morais, convergendo com o pensamento platônico.

A busca pela humanização do ser humano se evidencia nos estudos analisados neste artigo. Porém, as divergências destacadas têm relação, principalmente, com a participação plena na cidadania, ou seja, na integração à sociedade. A materialização do cidadão grego, era o homem detentor de posses que se valia de sua condição social e econômica para envolver-se nas decisões da polis. Já a teoria de Paulo Freire tem como fundamento o rompimento das relações opressoras e excludentes e, desse modo, constitui uma cidadania mais ampla que pode vir a garantir o acesso de todos aos direitos necessários à população, sem privilégios ou limitações.

Desse modo, a educação se demonstra como um caminho favorável para a transformação dos sujeitos. A educação libertadora de Paulo Freire sinaliza as dificuldades pelas quais trabalhadoras e trabalhadores vivenciam juntamente a suas famílias. O processo educativo deve enaltecer o ser humano como capaz de pensar de 
maneira autônoma e crítica. Em suma, Sócrates, Platão, Aristóteles e Freire sofreram repercussão das sociedades em que viveram ao deflagrar as incoerências e falhas nos sistemas epistemológicos educacionais de um ponto de vista filosófico e, consequentemente, da estrutura sociocultural existente. Em razão disso, Sócrates foi condenado à morte por instigar, via diálogo, a busca pelo autoconhecimento nos sujeitos bem como pelo conhecimento verdadeiro. Contudo, Platão e Aristóteles criam a Academia e o Liceu, respectivamente, como espaços de diálogo.

Já Paulo Freire foi exilado por razões intimamente relacionadas a suas propostas pedagógicas voltadas ao autorreconhecimento dos vínculos de opressão, especialmente em grupos marginalizados, apresentado fundo político e engajamento em prol da reflexão por uma educação popular e libertadora. Portanto, Freire buscou em sua trajetória, enquanto educador, humanizar o aprendizado e estimular o desenvolvimento de uma educação cidadã. Nesse sentido, essa percepção de uma pedagogia transformadora é o ponto de encontro dos princípios da paideia e de Freire na efetivação do cidadão no meio em que habita, concretizando a real e atuante cidadania.

Artigo recebido em: 01/04/2021

Aprovado para publicação em: 29/06/2021

THE PRESENCE OF THE PAIDEIA IN THE PEDAGOGY OF PAULO FREIRE: A PROPOSAL FOR CITIZEN EDUCATION

ABSTRACT: This article is characterized by a bibliographic research with a qualitative approach, presented in a Education Master Program, proposing to show the differences and approximations observed in the paideia and in Freire's freedom education. It is known that philosophy's fortification in Classical Greece allowed the development of new relations that focused mainly on the social participation of the greek citizen. Paulo Freire substantiate his educational principles in the dialogicity, autonomy and in the defense of essential rights for all. In this sense, the citizen education described in the paideia and in the works of Freire, exalt the human being as capable of transforming his or her realities through their humanization and understanding of their unfinished state, leading to a continuous educational process.

KEYWORDS: Education Fundamentals. Paideia. Paulo Freire. Freedom Education.

\section{LA PRESENCIA DE LA PAIDEIA EN LA PEDAGOGÍA DE PAULO FREIRE: UNA PROPUESTA DE EDUCACIÓN CIUDADANA}

RESUMEN: El presente artículo se caracteriza como una investigación bibliográfica de carácter cualitativo, presentado en la Maestría en Educación, proponiéndose a presentar los acercamientos y distanciamientos observados entre la paideia desarrollada en la antigüedad y la educación 
WALTRICK, A. P.; SANTOS, V.; GROSCH, M. S.

liberadora propuesta por el educador brasileño Paulo Freire. El fortalecimiento de la filosofia en la Grecia Clásica permitió constituir nuevas relaciones que priorizaron en especial la participación social de los ciudadanos griegos. Paulo Freire fundamenta sus princípios educativos en la dialogicidad, en la autonomía y en la defensa de los derechos esenciales de todos. En ese sentido, la educación ciudadana descrita en ambos enaltece el ser humano como capaz de transformar realidades en relación a su humanización y su comprensión de lo inacabado que conduce hacia un continuo proceso educativo.

PALABRAS-CLAVE: Fundamentos de la Educación. Paideia. Paulo Freire. Educación Liberadora.

\section{NOTAS}

1 - Ao nos referirmos ao conceito de Grécia Antiga concordamos com as ideias de Cambi (1999) compreendendo que na antiguidade os povos ocupantes dos territórios gregos não constituíram um conjunto de grupos sociais unificados como na maioria dos demais povos antigos. A Grécia Antiga é constituída por sociedades de diferentes etnias, oriundas das regiões da Europa e da Ásia, que possuíam semelhanças culturais em relação aos aspectos religiosos e culturais, mas com divergências nas organizações dos espaços urbanos.

2 - O filólogo alemão Werner Jaeger (2001) pontua o conceito de arete a partir da cultura grega, possui relação com os atributos e virtudes, pois a educação tem como princípio o preparo da aristocracia guerreira da época, a partir dos modelos mitológicos e heroicos que primavam pela beleza, justiça e bondade, representando "[...] o modelo ideal mais completo de formação ligada à excelência e ao valor [...]" (CAMBI, 1999, p. 77).

3 - As cidades-estados gregas eram organizadas a partir de um espaço central no qual se reuniam aqueles considerados como cidadãos para a tomada das decisões essenciais, sendo denominada de Ágora (ARANHA, 2006b), nessa praça central eram desenvolvidas "[...] funções urbanas importantes - direito, governo [sic.], comércio, indústria, religião e sociabilidade [...]" (MUMFORD, 1965, p. 198).

4 - A polis se desenvolveu na Grécia Antiga a partir do século VIII a.C. (ARANHA, 2006b). Sendo definida como, "[...] uma cidade-estado com forte unidade espiritual [...] que organiza um território, mas que sobretudo é aberta para o exterior (comércio, emigração, colonização) e administrada por regime ora monárquico, ora oligárquico, ora democrático, ora tirânico, mas no qual o poder é regulado por meio da ação de assembleias e de cargos eletivos" (CAMBI, 1999, p. 77).

5 - O termo paideia, segundo Jaeger (2001), tem seu surgimento entre os gregos a partir do século $V$ a.C. com sua consolidação no século IV a.C., onde se caracterizou enquanto ideal educacional. Nesse sentindo, a compreensão deste termo não se limita ao campo epistemológico da educação, é "[...] um conceito que engloba, ao mesmo tempo, diferentes dimensões, desde o de educação e de formação até o de cultura [...]" (CENCl; BALBOSCO; MÜHL, 2009, p. 134).

6 - Na Antiguidade os gregos se denominavam helenos, pois habitavam os territórios da Hélade, que era composto pelas cidades-estados ou polis que possuíam semelhanças culturais. Atualmente, essa região está dividida entre os países do Mar Mediterrâneo e Ásia Menor (FUNARI, 2011).

7 - A maiêutica é parte do método desenvolvido pelo filósofo Sócrates que pretendia estimular os indivíduos para a construção do autoconhecimento por meio da indagação, "[...] as perguntas de Sócrates se referiam a idéias [sic.], valores, práticas e comportamentos que os atenienses julgavam certos e verdadeiros em si mesmos e por si mesmos. Ao fazer suas perguntas e suscitar dúvidas, 
Sócrates os fazia pensar não só sobre si mesmos, mas também sobre a polis. Aquilo que parecia evidente acabava sendo percebido como duvidoso e incerto" (CHAUl, 2001, p. 38).

8 - A concepção de educação bancária criticada por Paulo Freire aponta os vínculos de dominância existentes nos modelos educativos dominantes, "[...] repercute como um anestésico, que inibe o poder de criar próprio dos educandos, camuflando qualquer possibilidade de refletir acerca das contradições e dos conflitos emergentes do cotidiano em que se insere a escola, o aluno. $\mathrm{Na}$ perspectiva freireana, a educação bancária tem o proposito de manter a imersão, a reprodução da consciência ingênua, da acriticidade" (SARTORI, 2008, p. 153, grifo do autor).

9 - Para Aranha (2006b), aedos e rapsodos são poetas que teriam vivido no que a história da Grécia chama de período homérico, e que tinham o compromisso na transmissão dos poemas e histórias orais pelas regiões ocupadas pelos gregos na Antiguidade. Entre esses contadores de história, destaca-se a figura de Homero, autor dos poemas épicos llíada e Odisseia.

10 - Segundo a história da Grécia, esses poemas teriam como autor Homero, poeta grego que viveu nos primórdios da sociedade grega (JAEGER, 2001). Esses poemas descrevem as origens da cultura grega, "[...] Ilíada que narra os eventos da guerra de Troia, [...] e a Odisseia, que conta a viagem de Ulisses de Troia a Ítaca, entremeada de vicissitudes, de provas de aventuras e de riscos [...]" (CAMBI, 1999, p. 76).

11 - A partir da descrição de Cambi (1999) que descreve o termo techne ao detalhar o ensino da oratória feita pelos sofistas aos grupos sociais que possuíam o direito nas tomadas de decisões na polis, desse modo, essa expressão tem relação com os métodos e práticas que transmitiam o conhecimento.

\section{REFERÊNCIAS}

ARANHA, M. L. de A. Filosofia da educação. 3 ed. São Paulo: Moderna, 2006a.

ARANHA, M. L. de A. História da educação e da pedagogia: geral e Brasil. 3 ed. São Paulo: Moderna, 2006b.

ARROYO, M. G. Artigo - Paulo Freire: outro paradigma pedagógico? Educação em Revista, Brasil, v. 35, 2019. Disponível em: <http://www.scielo.br/pdf/edur/v35/19826621-edur-35-e214631.pdf >. Acesso em: 25 mar. 2021.

CAMBI, F. História da pedagogia. São Paulo: Editora da UNESP, 1999.

CENCl, A. V.; DALBOSCO, C. A.; MÜHL, E. H. (org.). Sobre filosofia e educação: racionalidade, diversidade e formação pedagógica. Passo Fundo: UPF Editora, 2009.

CHAUI, M. Convite à filosofia. 12 ed. São Paulo: Ática, 2001.

FREIRE, P. Pedagogia da autonomia: saberes necessários à prática educativa. 48 ed. Rio de Janeiro: Paz e Terra, 2014b. 
WALTRICK, A. P.; SANTOS, V.; GROSCH, M. S

FREIRE, P. Pedagogia da esperança: um reencontro com a pedagogia do oprimido. 22 ed. São Paulo: Paz e Terra, 2015.

FREIRE, P. Pedagogia do oprimido. 57 ed. Rio de Janeiro: Paz e Terra, 2014a.

FREIRE, P.; FAUNDEZ, A. Por uma pedagogia da pergunta. 9 ed. Rio de Janeiro/São Paulo: Paz e Terra, 2019.

FUNARI, P. P. Grécia e Roma: vida pública e vida privada, cultura, pensamento e mitologia, amor e sexualidade. 5 ed. São Paulo: Contexto, 2011.

GIL, A. C. Como elaborar projetos de pesquisa. 6 ed. São Paulo: Atlas, 2018.

HAMMES, Lúcio Jorge; ZITKOSKI, Jaime José; BOMBASSARO, Luiz Carlos. Atualidade da Pedagogia do Oprimido: construindo esperança e mobilizando lutas emancipatórias. Revista e-Curriculum, Brasil, v. 16, n. 4, p. 1008-1028, out. dez. 2018. Disponível em: $<$ https://revistas.pucsp.br/curriculum/article/view/39440/27681>. Acesso em: 27 mar. 2021.

JAEGER, W. Paidéia: a formação do homem grego. 4 ed. São Paulo: Martins Fontes, 2001.

MINAYO, M. C. de S. O desafio da pesquisa social. In: MINAYO, Maria Cecília de Souza (org.); DESLANDES, Suely Ferreira; GOMES, Romeu. Pesquisa Social: teoria, método e criatividade. 1 re. Petrópolis: Vozes, 2016.

MUMFORD, L. A cidade na História: suas origens, suas transformações, suas perspectivas. Belo Horizonte: Itatiaia, 1965.

PLATÃO. A República. 9 ed. Lisboa: Fundação Calouste Gulbenkian, 2001.

SARTORI, J. Educação bancária/educação problematizadora. In: STRECK, D. R.; REDIN, E.; ZITKOSKI, J. J. (org.). Dicionário Paulo Freire. Belo Horizonte: Autêntica, 2008.

ZITKOSKI, J. J. Paulo Freire \& a educação. 2 ed. Belo Horizonte: Autêntica, 2010.

Ana Paula Waltrick: Mestre em Educação - PPGE - Programa de Pós Graduação em Educação da UNIPLAC - Universidade do Planalto Catarinense em Lages(SC) (2021).

Especialista em Educação Infantil - Universidade Positivo. Professora do Sistema Municipal da Educação de Lages/SC.

Orcid: http://orcid.org/0000-0003-2314-4173

E-mail:aninha@uniplaclages.edu.br

VANice dos SANTOS: Doutora em Educação - UFRGS (2012). Mestre e Licenciada em Filosofia - UNISINOS. Atuação profissional: Professora Adjunta no Departamento de Educação da Universidade Federal da Paraíba (UFPB/CCHSA/DE).

Inter-Ação, Goiânia, v.46, n. ed.especial, p. 993-1008, set. 2021. Disponível em: <http://dx.doi.org/10.5216/ia.v46ied.especial.68487>. 
Orcid: https://orcid.org/0000-0002-4852-5311

E-mail: vanicedossantos@gmail.com

Maria Selma Grosch: Doutora em Educação pelo Programa de Pós-Graduação em Educação UFSC- Universidade Federal de Santa Catarina (2011). Pós-Doutorado no PPGEd da UNOESC, sob a supervisão da Profa. Dra. Leda Scheibe (USC). Atuação profissional: Professora aposentada do Centro de Ciências da Educação da FURB. Atualmente é professora titular no PPGE- Programa de Pós Graduação em Educação da UNIPLAC- Universidade do Planalto Catarinense em Lages (SC).

Orcid: https://orcid.org/0000-0001-5874-2072

E-mail:selmagrosch@gmail.com

Este periódico utiliza a licença Creative Commons Attribution 3.0, para periódicos de acesso aberto (Open Archives Initiative - OAI). 